\title{
Avaliação da Qualidade dos Cursos de Graduação a Distância: o processo de acreditação como garantia de qualidade
}

\author{
Carla Netto \\ Pontifícia Universidade Católica do Rio Grande do Sul \\ netto.carla@gmail.com \\ Lucia M. M. Giraffa \\ Pontifícia Universidade Católica do Rio Grande do Sul \\ giraffa@pucrs.br
}

\begin{abstract}
Resumo: Este relato de pesquisa objetiva investigar a avaliação da qualidade na educação superior a distância, em tempos de expansão do Ensino Superior, na perspectiva dos sistemas de garantia de qualidade (acreditação). A pesquisa constitui-se numa análise qualitativa, descritiva, naturalístico-construtiva, contando, para tal, com levantamento bibliográfico. Faz parte da investigação a identificação das métricas utilizadas para medir qualidade em Educação a Distância no contexto internacional. Os resultados da pesquisa indicam que a acreditação pode ser uma boa opção de avaliação para a EAD, pois garante critérios e requisitos mínimos pré-definidos em termos de qualidade.
\end{abstract}

Palavras-chave: Qualidade em Educação Superior. Qualidade em Educação a Distância. Avaliação da qualidade.

Abstract: This research report investigates the quality of distance education in times of expansion of higher education from the perspective of quality assurance systems (accreditation, evaluation and audit). The study constitutes a qualitative analysis, descriptive, naturalistic-constructive, relying for this purpose with literature. It is part of the research to identify the metrics used to measure quality in distance education in the international and national levels. The results of research indicates that accreditation can be a good option for the evaluation of distance education, because it guarantees minimum requirements and criteria pre-defined in terms of quality.

Keywords: Quality in Higher Education. Quality in Distance Education. Quality assessment.

\section{Introdução}

Num contexto de expansão do Ensino Superior, a Educação a Distância passou a ser uma realidade, possibilitando a universalização e democratização do ensino. A perspectiva é que a Educação a Distância continue em ascensão tanto no contexto internacional como no nacional, passando cada vez mais a contribuir com a ampliação da oferta de Educação Superior.

Nesse cenário de crescimento, surge uma preocupação em torno da qualidade das ofertas de graduação a distância, gerando um interesse internacional por apropriados indicadores e mecanismos capazes de garantir a qualidade universitária nessa modalidade de ensino.

Avaliação sempre foi um tema polêmico, pois emite um juízo de valor sobre a qualidade das atividades, produtos, serviços e profissionais que atuam na instituição. No entanto, é necessário que as instituições sejam avaliadas para a garantia da qualidade. 
Ao mesmo tempo, é importante que a própria avaliação seja inovada.

No Brasil, os cursos de graduação (presenciais e a distância) são avaliados pelo MEC. Esse modelo adotado no país, onde o governo cria as regras e ele mesmo se avalia, tem provocado muita discussão no cenário nacional. Outro ponto que gera contestações diz respeito ao tipo de avaliação, que adota um caráter isomórfico, uniformizando uma regra para um país com grandes desigualdades sociais.

As práticas que vem sendo realizadas e as novas propostas que surgem em termos de avaliação no Brasil ainda adotam a mesma metodologia tanto para os cursos presenciais como para os cursos a distância. As modalidades de ensino são muito semelhantes, mas há grandes diferenças de uma para outra.

Este artigo objetiva investigar a avaliação da qualidade na educação superior a distância, em tempos de expansão do Ensino Superior, na perspectiva do sistema de garantia de qualidade (acreditação), visando a identificação de métricas utilizadas para medir qualidade em Educação no contexto internacional.

A acreditação pode ser uma boa opção de avaliação para um país tão grande e diversificado como o Brasil, pois permite adotar certificações com características locais, regionais, nacionais e internacionais, garantindo que uma instituição atende a critérios e requisitos mínimos pré-definidos em termos de qualidade.

\section{Avaliação da Qualidade no Ensino Superior}

A qualidade no Ensino Superior tem sido analisada e medida considerando seus componentes principais, como missão, fins, objetivos, insumos, processos e produtos. A busca pela qualidade na Educação tem se intensificado a cada dia, gerando um interesse internacional por apropriados indicadores de qualidade no Ensino Superior.

Essa preocupação por indicadores de qualidade busca responder questões como: Quais são os principais componentes da qualidade da Educação? Quais são as características da alta qualidade de um programa de Curso? Que qualidade apresenta um sistema de Educação?

Há duas abordagens metodológicas empregadas na avaliação da qualidade da Educação Superior, segundo Juliatto (2005):

- Categoria Quantitativa: As avaliações quantitativas são paradigmas métricos e contam com índices e medidas operacionalmente definidas e objetivas.

- Categoria Qualitativa: As avaliações qualitativas comportam alguma variedade de critérios mais subjetivos, embasadas em métodos de investigação naturalistas e etnográficos.

Métodos quantitativos têm sido usados no trato de matérias em que os dados já existem ou facilmente podem ser reunidos, como nos seguintes exemplos: teste de aptidão, registros estudantis, despesas registradas, coleções de biblioteca, dependências educativas, proporção de doutores no corpo docente e outros.

Os métodos qualitativos não enfatizam a objetividade no mesmo grau. Em vez disso, eles tentam capturar outras manifestações subjetivas da qualidade, mais infensas de serem traduzidas por medições numéricas, como a satisfação do estudante, o envolvimento pessoal do estudante e a interação do discente com o corpo docente. (Ibid. p.75). 
Tanto a abordagem qualitativa, como a quantitativa, são utilizadas na avaliação da qualidade da Educação Superior. Os métodos quantitativos têm sido predominantes ao longo do tempo, pois a utilização de medidas objetivas e padronizadas apresentam algumas vantagens. Pelo fato de carregarem dados numéricos, tornaram-se fáceis de usar e muito adequadas aos procedimentos de análise computacional, facilitando as comparações em séries históricas dentro da instituição e com outras instituições. Já a vantagem de utilização da abordagem qualitativa está na possibilidade de capturar alguns aspectos subjetivos da qualidade, incorporando na aferição apreciações pessoais dos sujeitos envolvidos no processo educativo.

Na avaliação da qualidade, conforme apontam Sanyal e Martin (2006), existem dois tipos de garantia de qualidade:

- Interna - A garantia interna da qualidade assegura que uma instituição tenha em funcionamento políticas e mecanismos que garantam que seus próprios objetivos e padrões sejam cumpridos.

- Externa - A garantia externa é realizada por uma organização que avalia o funcionamento do programa da instituição, a fim de determinar se os critérios prédeterminados são cumpridos.

A garantia da qualidade se dá em três níveis: instituição, programa e curso. Implica numa série de práticas entre as quais podemos distinguir três mecanismos:

- Auditoria de qualidade: verifica se uma instituição ou uma das suas unidades dispõe de um sistema de procedimentos de garantia de qualidade e determina sua adequação. As auditorias de qualidade são realizadas por pessoas que não têm vínculo com o objeto de análise e podem ser consideradas o primeiro passo do processo de garantia de qualidade. Noruega, Austrália, Nova Zelândia e África do Sul são países que utilizam esse enfoque.

- Avaliação da qualidade: implica em análises (estudo, planejamento e avaliação) da qualidade dos processos, práticas, programas e serviços da Educação Superior mediante técnicas, mecanismos e atividades apropriadas. O processo de avaliação da qualidade leva em conta o contexto (internacional, nacional, regional ou institucional), os métodos utilizados (autoavaliação, revisão por pares, informes), os níveis avaliados (sistema, instituição, programa), as áreas de avaliação (acadêmica, diretiva, rendimento ou resultados), os objetivos e as prioridades dos envolvidos. França é um exemplo deste enfoque.

- Acreditação: é o método de garantia externa de qualidade mais utilizado no contexto internacional. É o resultado de um processo mediante o qual uma entidade pública (governamental) ou privada (agência de acreditação), avalia a qualidade de uma instituição de Educação Superior em sua totalidade, um programa ou cursos efetivos de Ensino Superior, com o objetivo de reconhecer formalmente que cumpre determinados critérios ou padrões pré-determinados e conceder-lhes um selo de qualidade. A acreditação assegura um nível específico de qualidade, conforme a missão da instituição, os objetivos do programa e as expectativas de diferentes atores envolvidos, como estudantes. O processo de Acreditação normalmente resulta na concessão de um reconhecimento (sim ou não, uma pontuação numa escala de vários níveis, uma combinação de qualificação por letras, uma licença de funcionamento ou um reconhecimento condicional adiado) por um tempo determinado.

Como o processo de acreditação está cada vez mais difundido, pois faz um credenciamento em maior grau, uma vez que confere um selo de qualidade, vale uma reflexão mais aprofundada e esclarecedora sobre esse processo.

Um exemplo desse mecanismo de garantia de qualidade é o recente documento do

MEC,

disponível

em 
(http://portal.mec.gov.br/dmdocuments/convite_arquitetura_agronomia3.pdf), no qual fica explícita a intenção do governo brasileiro de criar mecanismos externos para avaliar a qualidade dos cursos e, também, estabelecer um padrão para essa avaliação.

\section{Acreditação na Educação Superior}

A grande expansão da Educação Superior tem gerado questionamentos a respeito da qualidade, levando a uma urgente revisão dos critérios mínimos para proteger o interesse dos envolvidos. A acreditação assegura o controle de qualidade (padrões mínimos) na Educação Superior, auxiliando na identificação de problemas (pontos negativos) e permitindo que medidas corretivas sejam adotadas para a melhora da qualidade.

Contudo, dado que a interpretação da qualidade varia conforme o contexto, a finalidade da acreditação para a garantia de qualidade também irá variar, levando a diferentes tipos de acreditação. Existem sete grandes tipos de acreditação, sendo que um dos tipos, a acreditação por cobertura geográfica, se subdivide em quatro categorias:

- acreditação obrigatória e voluntária;

- acreditação por adequação do objetivo versus o enfoque baseado em padrões;

- acreditação por cobertura geográfica;

o acreditação em âmbito subnacional;

o acreditação em âmbito nacional;

o acreditação em âmbito regional;

o acreditação em âmbito internacional;

- acreditação para o controle do Ensino Superior;

- acreditação por tipo de Educação Superior;

- acreditação por Unidade de Análise;

- acreditação para a Educação a Distância na Educação Superior.

\section{- Acreditação obrigatória e voluntária}

Sanyal e Martin (2006) apontam que uma das principais distinções na acreditação é ser obrigatória ou voluntária. A acreditação obrigatória requer que todas as instituições ou programas se submetam periodicamente ao processo de acreditação, comprovando os padrões mínimos de qualidade.

Na Argentina e na Colômbia, os cursos de Licenciatura, Medicina, Direito, Engenharia, entre outros que preparam os estudantes para exercerem as profissões que são consideradas de "vital” importância para o desenvolvimento e a segurança do país, requerem uma acreditação obrigatória. No entanto, a maioria dos sistemas de acreditação é voluntária. Assim, as instituições solicitam a acreditação. Índia, Estados Unidos e Nigéria são exemplos de países que adotam a acreditação voluntária.

\section{- Adequação do objetivo versus enfoque baseado em padrões}

O enfoque 'adequação do objetivo' verifica se a instituição de Educação Superior ou o programa alcançam o objetivo estabelecido (missão). Nesse enfoque, não é possível avaliar todas as instituições e os programas com os mesmos padrões, devido às especificidades de cada um.

No entanto, alguns autores concluem que nos sistemas de acreditação todas as instituições de Educação Superior devem cumprir com certos padrões (indicadores mínimos) e devem dar conta desses padrões. Essa visão conduz ao enfoque baseado em padrões. Nesse enfoque se estabelecem indicadores para os diferentes aspectos da 
qualidade. Dessa forma, todas as instituições ou programas devem cumprir com esses padrões, assegurando que possuem os requisitos mínimos, garantindo, assim, a qualidade.

\section{- Acreditação por cobertura geográfica}

O contexto nacional do sistema de Educação Superior deve ser levado em conta no processo de acreditação. Os itens a seguir analisam os sistemas de acreditação em diferentes níveis de cobertura geográfica: subnacional, nacional, regional e internacional.

\section{Acreditação em âmbito subnacional}

O termo subnacional é utilizado por Sanyal e Martin (2006) para ilustrar como funciona o processo de acreditação em sistemas federalistas com real independência dos Estados, como no caso dos Estados Unidos. Esse país apresenta um variado sistema de Educação Superior e uma tradição secular em acreditação.

A maioria dos sistemas de acreditação subnacionais avalia as instituições por inteiro e contam com padrões detalhados que incluem tanto as responsabilidades gerais que toda instituição deve cumprir, como os critérios para avaliar se alcançaram os padrões pré-determinados. Essas agências tentam manter um único conjunto de padrões e regulamentação, ao mesmo tempo em que reconhecem os diferentes tipos e missões das instituições.

\section{Acreditação em âmbito nacional}

As agências de acreditação nacionais atuam em todo o país e avaliam instituições inteiras, podendo ajustar o processo de avaliação, o foco de atenção do processo, os resultados da avaliação, a política sobre a divulgação dos resultados e o período de validade da decisão. Essas agências podem ser voluntárias e privadas, como na Alemanha, Japão, Filipinas e Estados Unidos.

Acreditação em âmbito regional

Em várias regiões do mundo foram sendo criadas redes de agências de garantia de qualidade. Na Europa, a acreditação está vinculada ao processo de Bolonha. Para promover a transparência, compatibilidade e equiparidade entre os diversos sistemas de Educação Superior da Europa, os Ministros da Educação de 29 países firmaram a Declaração de Bolonha, em 1999. O resultado foi o estabelecimento de padrões e diretrizes para a Garantia de Qualidade no Espaço Europeu de Educação Superior, publicado pela Associação Européia de Garantia de Qualidade na Educação Superior (ENQA).

Acreditação em âmbito internacional

O surgimento de uma perspectiva internacional de acreditação se deve à crescente mobilidade de estudantes, à necessidade de reconhecimento internacional dos títulos, à rápida expansão da Educação a Distância, das universidades virtuais e da aprendizagem virtual dentro dos limites nacionais, regionais e continentais.

Para a acreditação internacional de programas específicos normalmente é usada a ISO ${ }^{1}$ 9000. Segundo Sanyal e Martín (2006), os benefícios de implantar o padrão ISO 9000 são os seguintes: melhora a imagem da instituição por ter um padrão aceito internacionalmente; demonstra que a instituição dispõe de um sistema de gestão de qualidade documentado; proporciona a base para um programa de gestão de qualidade

\footnotetext{
1 A Organização Internacional de Normatização (ISO), com sede em Genebra, é uma federação mundial de entidades de padrões nacionais responsáveis por criar padrões para cada país. A ISO começou originariamente acreditando empresas, mas agora contempla também as instituições educativas. O padrão ISO 9000 foi criado para garantir que a Educação Superior oferecida por um país seja reconhecida e aceita em todo o mundo.
} 
total e reduz a insatisfação dos envolvidos; aumenta a conscientização a respeito de qualidade, motivação e cooperação; está focada na formação e no desenvolvimento profissional; melhora a comunicação internacional; garante o reconhecimento mundial da instituição ou do programa, satisfaz a clientela, a sociedade e garante que os graduados tenham oportunidades de emprego; estabelece um ponto de partida para a melhora contínua da produtividade e da eficácia; reduz as largas auditorias feitas pelos reguladores; prepara a instituição para os futuros requisitos do mercado.

\section{- Acreditação para o controle do Ensino Superior}

Uma das questões que surge com a acreditação é se ela deve ser aplicada igualmente aos setores público e privado. Em alguns países foram instaurados sistemas de acreditação apenas para o setor privado, como em Omã, na Arábia. No entanto, muitos países estão se dando conta de que tanto as instituições privadas como as públicas deveriam buscar alcançar os objetivos nacionais de desenvolvimento. Assim, a acreditação passa a ser algo importante para ambas.

\section{- Acreditação por tipo de Educação Superior}

A acreditação é realizada não só nas Universidades, mas também em Centros Universitários, Faculdades, Escolas Técnicas, entre outras. Sendo assim, os procedimentos e critérios da acreditação podem ser distintos e, em consequência, são necessárias diferentes agências de acreditação.

\section{- Acreditação por unidade de análise}

A acreditação pode ser realizada na instituição como um todo, juntamente com os programas ou num curso específico. A acreditação institucional está focada na avaliação da missão, administração, programas acadêmicos, corpo docente, recursos para a aprendizagem, estudantes, serviços, infraestrutura e recursos financeiros. A acreditação programática está voltada aos programas educativos. Nesse sentido, para que a acreditação institucional seja efetiva, os programas acadêmicos devem ser considerados na avaliação. Ambas acreditações são complementares, alguns países usam a acreditação institucional e a programática num único modelo.

\section{- Acreditação para a Educação a Distância na Educação Superior}

Diante da expansão do Ensino Superior a grande dúvida que surge está relacionada com a qualidade dessas ofertas e os mecanismos capazes de garantir a qualidade de um curso nessa modalidade. Nesse sentido, Sanyal e Martin (2006) afirmam que é preciso uma acreditação especial que proteja os interesses dos estudantes e dos países.

A Índia possui um Conselho Nacional de Avaliação e Acreditação - NAAC (http://naacindia.org/), que avalia e acredita todo o setor de Educação Superior no país (em torno de 360 Universidades e 14.000 Escolas Universitárias). Mesmo assim, estabeleceu um Conselho de Educação a Distância (DEC) para supervisionar a avaliação e a acreditação do sistema de EAD no país.

Segundo Kanwar e Koul (2006), para garantir a qualidade em todas as iniciativas em EAD, é necessário que as instituições ou os países, por si só ou de forma global, estabeleçam mecanismos inovadores que garantam a qualidade. Algumas das razões pelas quais se faz necessário esses mecanismos são:

1. como conseqüência da democratização em quase todo o mundo, do reconhecimento da Educação como um direito humano, da globalização, surge a necessidade de ampliar a gama de ofertas e flexibilizar o acesso ao Ensino Superior; 
2. o aumento da demanda de programas e cursos que satisfaçam as necessidades do mercado de trabalho, a diversidade de trabalhadores, as crescentes aspirações das gerações mais jovens e do novo perfil do estudante, faz-se necessária uma oferta de qualidade que seja, de uma só vez, socialmente relevante, educativamente sólida e orientada ao desenvolvimento;

3. nos casos em que a EAD é vista com um certo receio, a acreditação serve não só para garantir a qualidade dos programas, mas para demonstrar que a instituição está preocupada em ofertar uma Educação de qualidade;

4. o peso da tradição do ensino presencial impacta no estabelecimento de um novo sistema educativo que seja socialmente receptivo, exceto se os objetivos institucionais, a legislação, a infraestrutura, os recursos e as práticas sejam revistas e modificadas, tendo a qualidade como o atributo comum que sustente cada uma das modalidades;

5. o sucesso da aplicação das Tecnologias de Comunicação e de Informação (TICs) depende da qualidade da política em questão, da infraestrutura, dos recursos humanos e do ambiente em geral. As instituições precisam considerar esses pré-requisitos de qualidade na aplicação dessas tecnologias, assim como garantir a sua sustentabilidade;

6. as TICs ajudam a promover a Educação em qualquer modalidade, diversificando as possibilidades das instituições que as oferecem. Essa situação evidencia a necessidade de busca de qualidade em produtos e serviços, para que não tenham que contentar-se em proporcionar uma Educação com qualidade inferior em suas instituições, correndo o risco de desaparecerem;

7. o novo perfil dos estudantes (oriundos da era digital) ${ }^{2}$ está transformando as interrelações didáticas. Essa situação revela outro aspecto relacionado com a qualidade no processo de ensino e aprendizagem, dentro de um paradigma educativo conectivista.

Essas razões abordadas anteriormente são comuns nas diferentes instituições de diversos países. No entanto, cada um percebe e enfoca os itens de qualidade de forma diferente, seguindo algum dos muitos enfoques disponíveis: o enfoque Baldrige ${ }^{3}$, o enfoque de Kaplan e Norton ${ }^{4}$, o enfoque Barnett ${ }^{5}$, o enfoque da Gestão de Qualidade

2 Os alunos oriundos da era digital, chamados de nativos digitais possuem um novo perfil, pois desenvolveram formas diferenciadas de interação com o mundo e, consequentemente, novas formas de aprendizagem. "Ao invés de utilizar um texto, por exemplo, preferem um hipertexto, uma música ou mesmo um jogo de vídeo game. Estão muito mais inclinados a utilizar novos formatos de mídia.” (CUNHA, 2009, p. 19).

3 O enfoque Baldrige de gestão de qualidade analisa os seguintes critérios para a Educação: 1) liderança,

2) planejamento estratégico, 3) estudantes, partes interessadas e foco no mercado, 4) informação, análise e gerenciamento do conhecimento, 5) enfoque nas pessoas e 6) gerenciamento de processos.

4 Desenvolvido por Robert Kaplan e David Norton, na década de 1990, esse enfoque envolve quatro perspectivas (Perspectiva Financeira; Perspectiva do Cliente; Perspectiva de Processos Internos e Perspectiva de Aprendizado e Crescimento).

5 Na visão de Ronald Barnett, antes de formar opinião consistente sobre qualidade em ES, é preciso se ter uma razoável concepção da própria educação superior. Segundo ele, quatro perspectivas podem sustentar abordagens contemporâneas de educação superior: (i) educação superior como produção de recursos humanos qualificados, (ii) educação superior como formação para a carreira de pesquisador, (iii) educação superior como gerenciamento eficiente da oferta de ensino e (iv) educação superior como meio de ampliar as oportunidades na vida. Diante dessas perspectivas de educação superior, ele propõe as concepções "objetivista, relativista e desenvolvimentista” da qualidade. A visão objetivista enfatiza que é possível identificar e quantificar certos aspectos da educação superior que podem ser aplicados de forma universal a todas instituições, Já a abordagem relativista tem sua ênfase na política pública e no embasamento teórico. Barnett afirma que a concepção objetivista é altamente insensível às diferenças existentes entre as instituições de educação superior e que a concepção relativista carece de uma clara definição do que atualmente se pode considerar "educação superior". Devido a essas limitações, o ele propõe uma terceira perspectiva, designada de "Abordagem desenvolvimentista da qualidade", na qual os 
Total $^{6}$, o ISO 9000:20007 , entre outros.

Embora esses enfoques tenham sido inicialmente desenvolvidos para o setor empresarial, eles tem sido modificados sucessivamente para serem aplicados tanto nas instituições educativas como na gestão de sistemas em Educação a Distância. Para Kanwar e Koul (2006), as práticas mais notáveis em acreditação são as desenvolvidas na Austrália, no Reino Unido e nos Estados Unidos.

A Agência de Qualidade das Universidades Australianas (AUQA) (http://www.auqa.edu.au/), criada em março de 2000, é um organismo independente, sem fins lucrativos, que promove a qualidade na Educação Superior, incluindo a Educação a Distância. A AUQA não impõe um código de boas práticas nas universidades australianas, já que supõe que essas tenham seus próprios sistemas de garantia de qualidade. A Agência realiza auditorias a pedido da própria instituição e identifica as melhores práticas, assim como aquelas áreas que precisam ser aperfeiçoadas.

A Agência de Garantia de Qualidade para a Educação Superior (QAAHE), criada no Reino Unido, em 1997, desenvolveu um código de boas práticas com 10 itens, que incluem as atividades colaborativas, metodologia, avaliação, entre outros, e as diretivas para seguir esses princípios.

As instituições, inclusive as que oferecem Educação a Distância, devem fornecer dados de autoavaliação, explicando como aplicam tais princípios. A QAAHE revisa o conteúdo dos dados apresentados pelas instituições, realiza auditorias e qualifica sua avaliação em termos de 'ampla confiança', 'confiança limitada' e 'nenhuma confiança' no funcionamento das instituições auditadas. A avaliação do QAAHE não só protege as normas educativas no país, como também assegura ao público a melhora contínua da qualidade no processo educativo.

Outro exemplo de prática notável em acreditação, segundo os autores citados, é o Conselho de Acreditação da Educação Superior - CHEA (http://www.chea.org/), estabelecido em 1997, pelos Estados Unidos, com o objetivo de proporcionar um reconhecimento às agências de acreditação, que estão sujeitas a revisões periódicas para continuarem ou não atuando.

Outras organizações de acreditação que atuam na modalidade a distância são a Rede de Qualidade na Ásia-Pacífico (APQN) e a Rede Européia para a Garantia da Qualidade na Educação Superior (ENQA).

A APQN (http://www.apqn.org/), estabelecida em Hong Kong, em 2003, auxilia as agências de garantia de qualidade do Ensino Superior, numa região que possui mais

membros da organização realizam uma auto-avaliação, com foco na melhoria da qualidade da instituição. (BERTOLIN, 2009)

6 O enfoque Gestão de Qualidade Total é voltado para o alcance da satisfação do cliente através de um processo de melhoria contínua dos produtos e serviços gerados pela empresa, contando com a participação de todos os membros da instituição. Este enfoque tem cinco pressupostos básicos: 1) qualidade é definida do ponto de vista do cliente; 2) qualidade é relacionada com lucratividade em ambos os lados: do mercado e de custos; 3) qualidade é visualizada como uma arma competitiva; 4) qualidade é construída desde o processo de planejamento estratégico; 5) qualidade requer um compromisso que abranja todos os membros da organização.

7 A ISO, International Organization for Standardization, foi fundada em 1947, tendo como meta o estabelecimento de normas e padrões técnicos internacionais sobre sistemas de gestão da qualidade, para a garantia da qualidade. Em 1987, quando foi criada a série ISO 9000 (a primeira série compreendia cinco normas, de ISO 9000 a ISO 9004), ficou determinado que elas seriam revisadas periodicamente, para o aprimoramento contínuo do conteúdo e para refletirem as inovações inerentes aos processos organizacionais. Na primeira revisão, em 1994, manteve-se a série de normas ISO 9000 a ISO 9004. A revisão realizada em 2000 agrupou tudo sob a apresentação única de ISO 9000. No entanto, para diferenciá-la da anterior, já é empreganda a grafia ISO 9000:2000 em publicações e documentos diversos. 
da metade da população mundial, a melhorarem suas práticas e apoia o estabelecimento de novas agências de garantia de qualidade. A ENQA publicou, em 2005, o documento Normas e Diretrizes para a Garantia da Qualidade na Educação Superior Européia que delineia as normas e procedimentos para a avaliação interna e externa da instituição, assim como as diretrizes que devem seguir as agências de garantia de qualidade. Em 2009 foi lançada a $3^{\mathrm{a}}$ versão desse documento, disponível no endereço http://www.enqa.eu/files/ESG_3edition\%20(2).pdf .

\section{Acreditação no Brasil}

Pode-se dizer que o Brasil deu seus primeiros passos em Acreditação no ano de 2003, quando foi implementado o Mecanismo Experimental de Avaliação (MEXA) e aplicado nos cursos de Agronomia, Engenharia e Medicina entre 2003 e 2006, com o objetivo de estabelecer padrão de qualidade, com critérios acordados entre os países integrantes da Rede de Agência Nacional de Acreditação do Mercosul (RANA).

A Comissão Nacional de Avaliação da Educação Superior (CONAES), órgão colegiado de coordenação e supervisão do Sistema Nacional de Avaliação da Educação Superior (SINAES), é integrante, no Brasil, da RANA. Essa Rede é responsável pela formatação das diretrizes do Sistema MERCOSUL de Acreditação dos Cursos.

No Brasil, doze cursos foram aprovados pelo MEXA e receberam um selo de qualidade de Acreditação do MERCOSUL. Três cursos de Agronomia (Universidade de Brasília, Universidade Federal de Viçosa e Universidade Estadual de Londrina), três cursos de Medicina (Santa Casa de Saúde de São Paulo, Universidade Estadual de Londrina e Universidade Federal de São Paulo) e seis cursos de Engenharia foram aprovados, dois de Engenharia Elétrica (Universidade de São Paulo - USP e Universidade Federal de Campina Grande, dois de Engenharia Mecânica (Universidade Federal de Uberlândia e Universidade Federal do Rio de Janeiro) e dois de Engenharia Química (PUC-Rio e Unicamp).

Num acordo firmado em junho de 2008, em San Miguel de Tucumán, na Argentina, ficou definido que o processo de credenciamento será contínuo, com convocações periódicas, coordenadas pela Rede de Agências Nacionais de Credenciamento e que participação das instituições será voluntária. O processo de credenciamento de um curso considerará, no mínimo, os seguintes aspectos: contexto institucional, projeto acadêmico, recursos humanos e infraestrutura. O credenciamento $^{8}$ outorgado terá vigor de seis anos.

A acreditação não tem fins regulatórios. Assim, quem for estudar numa universidade no exterior passará pelo processo de revalidação de diploma. A diferença é que o processo de revalidação será mais rápido, porque a qualidade do curso já foi atestada.

\section{Considerações Finais}

Este artigo investigou algumas práticas que vem sendo realizadas em outros países na busca pela qualidade da Educação, procurando identificar as métricas de qualidade utilizadas para avaliar cursos a distância.

As agências e organizações de acreditação citadas delineiam o processo e o significado da acreditação na Educação a Distância, evidenciando que o centro do

8 O credenciamento é resultado do processo de avaliação por meio do qual é certificada a qualidade acadêmica dos cursos de graduação estabelecendo que satisfazem o perfil do graduado e os critérios de qualidade previamente aprovados no âmbito regional para cada diploma. 
processo é o significado da combinação entre a avaliação interna e externa. Nesse sentido, uma cultura de qualidade em EAD se define em termos dessa combinação.

Uma cultura de qualidade pode ser definida como uma cultura institucional que promove a introdução de um sistema interno de garantia de qualidade, valoriza a implementação de garantia externa de qualidade e se centra mais na aprendizagem do que no ensino.

A acreditação em Educação a Distância não deve ser confundida com uma cultura de qualidade em EAD. Acreditação é um mecanismo de avaliação que ajuda a comparar padrões de qualidade entre instituições e países, facilitando a tomada de decisão por bons cursos virtuais e protegendo o padrão de qualidade na Educação a Distância.

\section{Referências}

CUNHA, Patricia Freire Vieira da. Uma Investigação acerca do uso Educacional do Ambiente Second Life no Ensino de Matemática. 2009. 79 f. Dissertação (Mestrado em Educação em Ciências e Matemática) - Faculdade de Física, PUCRS: Porto Alegre, 2009.

JULIATTO, Clemente Ivo. A Universidade em Busca da Excelência: um estudo sobre a qualidade da educação. 2. ed. Curitiba: Universitária Champagnat, 2005.

KANWAR, Asha; KOUL, Badri N. La Garantia de La Calidad y La Acreditacíon de La Educación Superior a Distancia em La Commnwealth. In: La Educación Superior en el Mundo 2007: acreditación para la garantía de la calidad: ¿ Qué está en juego? Barcelona: Ediciones Mundi-Prensa, 2006. Anais GUNI - 2006.

SANYAL, Bikas C; MARTIN, Michaela. Garantía de La Calidad y el Papel de la Acreditación: Uma Visión Global. In: La Educación Superior en el Mundo 2007: acreditación para la garantía de la calidad: ¿ Qué está en juego? Barcelona: Ediciones Mundi-Prensa, 2006. Anais GUNI - 2006. 